\title{
Takayasu's Arteritis: Rare Cause of Hypertension in Children
}

\author{
Lamichhane RD' ${ }^{1}$, Chapagain RH$^{2}$
}

\section{Abstract}

Takayasu arteritis (TA) is a large vessel vasculitis that involves the aorta, its major branches and pulmonary arteries. Diagnosis of TA during childhood remains challenging due to the non-specific symptoms. We report a six years age boy with unresolved hypertension who was later diagnosed as childhood TA. Oral corticosteroid was started $2 \mathrm{mg} / \mathrm{kg} /$ day. TA is rare in children; Childhood TA must be considered in children who present with, hypertension and increased acute phase reactants.

Key words: Children, Takayasu's arteritis, Steroids

\section{Introduction}

$\mathrm{T}$ akayasu arteritis (TA) is a large vessel vasculitis that involves the aorta, its major branches and pulmonary arteries. Diagnosis of TA during childhood remains challenging due to the non-specific symptoms. The estimated worldwide incidence is 2.6 cases per million per year. The disease has been mainly studied in Japan but Western studies have also been published ${ }^{1}$.

The first manifestation of Takayasu's arteritis was recognized between the age of 11 and 48 years. In 66 of the 84 patients $(78.5 \%)$, it was between the ages of 11 and 29 years $^{2}$. In a retrospective review of 107 charts of patients with TA studied during a 19 year period up to May, 1974, most patients' ages ranged from 11 to 30 years (80 per cent). The youngest was four years old ${ }^{1}$. A recent review article reported a total of 241 TA cases published in the paediatric age group ${ }^{3}$

\section{The Case}

A six years age boy came in with persistently high blood pressure since four months. He also has history of swelling of whole body which gradually started from eyes, face to whole body. No history of haematuria, loss of consciousness, sore throat, skin lesions. Patient was diagnosed as Post Streptococcal Glomerulonephritis and was admitted in other hospital. Hypertension Grade-II and discharged on Amlodipine $5 \mathrm{mg} /$ day Enalapril $0.08 \mathrm{mg} / \mathrm{kg} /$ day. However medication was discontinued since the past four days and BP was still persistently high so was planned for renal biopsy and was referred to our hospital. On examination patient was well built, afebrile, BP: 130/90mm of $\mathrm{Hg}$ $\left(>99^{\text {th }}\right.$ percentile) which was persistently high in successive days and hard to record in lower limbs. Other systems were essentially normal. Investigations were as follows.
${ }^{1}$ Dr. Reshma Dhakal Lamichhane MBBS, MD, Paediatrican, Kanti Children's Hospital, Kathmandu, ${ }^{2} \mathrm{Dr}$. Ram Hari Chapagain, MBBS, MD, Senior Consultant Paediatrician, Kanti Children's Hospital and Assistant Professor of Paediatrics National Academy of Medical Sciences (NAMS).

\section{Address for correspondence \\ Dr. Reshma Dhakal Lamichhane \\ E-mail: reshmadhakallamichhane@gmail.com}

\section{How to cite}

Dhakal RL, Chapagain RH. Takayasu's Arteritis: Rare Cause of Hypertensionln Children. J Nepal Paediatr Soc 2018;38(2):140-142.

doi:http://dx.doi.org/10.3126/jnps.v38i2.20551

This work is licensed under a Creative Commons Attribution 3.0 License.

\section{(c) (i)}




\begin{tabular}{ll}
\hline Day 1 of admission & $\begin{array}{l}\text { Erythrocyte Sedimentation Rate was } 52 \text { (high), platelets 3,60,000/cumm. Anti } \\
\text { Streptolysin "O" titre was positive. }\end{array}$ \\
\hline Day 2 of Admission & ANA, AntiDsDNA, PT, APTT were with in Normal Limit \\
\hline Day 3 of admission ECHO & moderate LV systolic dysfunction with mild MR dilated LA, LV \\
\hline & $\begin{array}{l}\text { long segment circumferential smooth wall thickening of the thoracic and abdominal } \\
\text { aortic wall with progressive narrowing of its lumen. Similar wall thickening of the SMA, } \\
\text { Day 4 of admission CT } \\
\text { Angiogram }\end{array}$ \\
$\begin{array}{l}\text { bilateral main renal artery with marked stenosis of left renal artery. Thrombus of right } \\
\text { common iliac artery with reformation with collaterals just before its bifurcation. Smaller } \\
\text { left Kidney. S/O Takayasu 's Arteritis }\end{array}$ \\
\hline
\end{tabular}

Our patient was started on Prednisolone $2 \mathrm{mg} / \mathrm{kg} /$ day. Hypertension was treated with antihypertensive agents, since aggressive therapy was necessary to prevent complications. Patient also received Amlodipine $5 \mathrm{mg} /$ day Enalapril $0.08 \mathrm{mg} / \mathrm{kg} /$ day.

\section{Discussion}

Takayasu's disease is a chronic inflammatory disease of large and medium sized arteries, involving the aorta and its main branches, the pulmonary arteries, and the coronary tree. Since the original report of Takayasu's disease in $1908^{4}$, the estimated worldwide incidence is 2.6 cases per million per year, with women more commonly affected than men. Peak onset is in individuals in their 30s. The disease has been mainly studied in Japan but Western studies have also been published $^{5}$. Cardiac features are present in up to $40 \%$ of cases. One case reported in 6years old with cardiac feature $^{6}$. The aetiology and the precise pathogenesis of Takayasu's arteritis are still unknown but much has been learnt about the disease since its initial description by M. Takayasu, a Japanese ophthalmologist in $1908^{7}$. This disease is the commonest cause of reno-vascular hypertension in Asian children ${ }^{8}$. Arterial hypertension is the most common finding on physical examination of children which was also present in our case (82.6\%), and often suggests the diagnosis but we could not find exact prevalence data. The tests of inflammatory activity are elevated in most cases ${ }^{9}$ which is similarly to our results. In our case, this finding and their clinical features supported the request for imaging studies and helped to establish our patients' diagnosis.

This is diagnosed according to the criteria adopted by the American College of Rheumatology are shown in Table $1^{9}$.

For purposes of classification, a patient shall be said to have Takayasu's arteritis if at least three of these six criteria are present. The presence of any three or more criteria yields a sensitivity of $90.5 \%$ and a specificity of $97.8 \%$

Treatment: The two most important goals of treatment are controlling the inflammatory process and controlling the hypertension. Corticosteroids are the most important therapeutic agents.Therapy is continued until patients achieve remission. Corticosteroids are still the mainstay of treatment ${ }^{10}$. Glucocorticoids are an effective agent for most patients with active TA. Remission has been achieved in $60 \%$ of patients treated with glucocorticoids ${ }^{11}$. Our patient was also started on steroid (prednisolone) $2 \mathrm{mg} / \mathrm{kg} /$ day. Antiplatelet agents and heparin may prove useful in preventing stroke. Due to the rarity of the disease, we could not find controlled studies of medical treatment of children with TA.

Anti-inflammatory therapy can lead to dramatic improvement in TA. The mortality rate in children, though, is as high as $35 \%{ }^{12}$. The outcome depends on the

Table 1: Criteria of American College of Rheumatology for the Classification of Takayasu's Arteritis

\begin{tabular}{ll}
\hline Criteria & Definition \\
\hline $\begin{array}{l}\text { Age at disease onset in year } \\
\text { Claudication of extremities }\end{array}$ & Development of symptoms or findings related to Takayasu's arteritis at age \\
\hline Decreased brachial artery pulse & $\begin{array}{l}\text { Development and worsening of fatigue and discomfort in muscles of one or } \\
\text { more extremity while in use, especially the upper extremities. }\end{array}$ \\
\hline Blood pressure difference $>10 \mathrm{mmHg} g$ & $\begin{array}{l}\text { Decreased pulsation of one or both brachial arteries. } \\
\text { Bruit over subclavian arteries or aorta }>10 \mathrm{mmHg} \text { in systolic blood pressure between arms. }\end{array}$ \\
\hline $\begin{array}{l}\text { Bruit audible on auscultation over one or both subclavian arteries or } \\
\text { abdominal aorta. }\end{array}$ \\
\hline Arteriogram abnormality & $\begin{array}{l}\text { Arteriographic narrowing or occlusion of the entire aorta, its primary } \\
\text { branches, or large arteries in the proximal upper or lower extremities, not } \\
\text { due to arteriosclerosis, fibro-muscular dysplasia, or similar causes: changes } \\
\text { usually focal or segmental. }\end{array}$ \\
\hline
\end{tabular}


vessel involvement and on the severity of hypertension. Hypertension is treated with antihypertensive agents, and aggressive therapy is necessary to prevent complications. It was difficult to control hypertension in this our patient, he received Amlodipine $5 \mathrm{mg} /$ day and Enalapril $0.08 \mathrm{mg} / \mathrm{kg} /$ day at discharge. In a Turkish survey, one patient with pulmonary artery stenosis died within the first 3 years and two patients underwent nephrectomy ${ }^{13}$. In South Africa, the mortality rate was $22.5 \%$; 7 of 31 patients died because of hypertension or complications after kidney transplantation. One patient died after EBV-associated haemophagocytic syndrome ${ }^{14}$. Prevention of organ damage may avoid worse outcome.

Prognosis: Takayasu's arteritis in children is a serious illness and a mortality of $10-30 \%$ has been reported on follow up. In his prospective studies on the natural history of Takayasu's arteritis, Ishikawa estimated a 5-yearsurvival of $83 \%$ in all patients with Takayasu's

\section{References}

1. Ishikawa K. Diagnostic approach and proposed criteria for the clinical diagnosis of Takayasu's arteriopathy. J Am Coll Cardiol 1988;12:964-72. DOI: 10.1016/07351097(88)90462-7

2. Numano F. Differences in clinical presentation and outcome in different countries for Takayasu's arteritis. Curr Opin Rheumatol 1997;9:12-5. DOI: 10.4081/ hi.2006.66

3. Nakao K, Ikeda M, Kimata S, Niitani H, Niyahara M. Takayasu's's arteritis: Clinical report of eighty-four cases and immunological studies of seven cases. Circulation 1967;35:1141-55.

4. Kerr GS, Hallahan CW, Giordano J, et al. Takayasu arteritis. Ann Intern Med 1994;120:919-29. DOI: 10.1093/rheumatology/kev366.

5. Lande A, Bard R, Rossi P, Castrucci A. Takayasu's arteritis: A worldwide entity. NY State J Med 1976;76:1477-82.

6. Fabi $M$, Brighenti $M$, Donti $A$, et al.Tricky case of Takayasu arteritis in a young child presenting with heart failure and femoral pulses. Arch Dis Child. 2018 Apr 19. pii: archdischild-2017-314663. doi: 10.1136/ archdischild-2017-314663. [Epub ahead of print]

7. Takayasu M. Case with unusual changes of the central vessels in the retina (in Japanese) Acta Soc Ophthal Jap 1908;12:554-55. arteritis and a 10 -year survival of $58 \%$ in patients with severe disease. There are few follow-up studies in children, and the mortality rate has ranged from $21 \%$ to $40 \%$ in the short term. ${ }^{15}$.More recently, the prognosis has significantly improved due to interventional procedures for the treatment of renal and aortic stenosis. We could not find out the Long term follow up data on children is not available.

\section{Conclusion}

We conclude that TA is a rare disease in a paediatric setting, and also that it has to be considered in cases of unexplained hypertension or unexplained inflammatory syndromes without signs of localization. A thorough physical examination can lead to the correct diagnosis if pulses cannot be felt, even if these are not constant findings. Since the disease can be progressive and lifethreatening, an early recognition is vital in order to start immunosuppression

8. Chugh KS, Sakhuja V. Takayasu's arteritis as a cause of renovascular hypertension in Asian countries. Am J Nephrol 1992;306:464-65. DOI:10.1159/000168409

9. Brunner J, Feldman BM, Tyrrell PN, KuemmerleDeschner JB, Zimmerhackl LB, Gassner I et al. Takayasu arteritis in children and adolescents. Rheumatology (Oxford) 2010;49(10):1806-14. DOI: 10.4103/0974-2069.107235

10. Johnston SL, Lock RJ, Gompels MM. Takayasu arteritis: a review. J Clin Pathol 2002; 55:481-86

11. Hoffman GS. Takayasu arteritis: lessons from the American National Institutes of Health experience. Int J Cardiol 1996;54:Suppl S99-102.

12. Morales E, Pineda C, Martinez-Lavin M. Takayasu's arteritis in children. J Rheumatol 1991;18:10814. DOI: $10.1186 / 1546-0096-6-17$

13. Cakar N, Yalcinkaya F, Duzova A, et al. Takayasu arteritis in children. J Rheumatol 2008;35:913-19. DOI: 10.5606/tjr.2011.025

14. Hahn D, Thomson PD, Kala U, Beale PG, Levin SE. A review of Takayasu's arteritis in children in Gauteng, South Africa. Pediatr Nephrol 1998;12:668-75 DOI: $10.1186 / 1546-0096-6-17$.

15. Ishikawa K. Survival and morbidity after diagnosis of occlusive thromboaortopathy (Takayasu's arteritis). Am J Cardiol 1981;47:1026-32. DOI: 10.1016/00029149(81)90208-3 